\title{
The Temporal-spatial Difference and Convergence of Tourism Economy in ZheJiang Province
}

\author{
Lan PAN \& Zesun LUO \\ School of Management, Xiamen University, Xiamen, China
}

Wei ZHANG

Information Institute, Zhejiang University of Finance \& Economics, Zhejiang, China

\begin{abstract}
Using coefficient of variation and Gini coefficient, this paper measures difference of tourism economy in Zhejiang Province through structural and regional decomposition, then uses convergence theory of economic growth to check the existence of convergence. The results show that total tourism economic difference tends to reduce gradually. The tourism economic difference features are as follow: It is mainly contributed by domestic tourism in structure, but difference of inbound tourism is higher than that of domestic tourism. While it is mainly contributed by the inter-regional difference, and the inter-regional difference is greater than difference within the region. Convergence test shows that tourism economy in Zhejiang Province is converging, that is, per capita output of regional tourism will converge to the same steady-state level in the long-term. Meanwhile, $\alpha$-convergence and absolute $\beta$-convergence have been identified, but there is no club convergence, meaning that polarization phenomenon does not exist.
\end{abstract}

KEYWORD: tourism economy; regional difference; convergence

\section{INTRODUCTION}

Academic researches on regional differences of tourism economy become hot now. At present, domestic related research is mainly from national or provincial point of view, using relevant statistical indicators (such as coefficient of variation, Theil index, Gini coefficient, etc.) to describe the different characters of the regional tourism economy on spatial and temporal views. By decomposing these differences, we can design coordinated policies to help the development of regional tourism. These research results can have certain policy guidance to promote the balanced development of regional tourism.

In the 1960s, economists Solow and Swan (1956) discovered the phenomenon of economic convergence when they studied the Economic Growth Theory, and then Barro and Sala-I-Martin (1995) proposed an Econometric Model to test the convergence of economic growth, and extensive literatures emerged in this field. Convergence as an indicator to measure the imbalance of regional economic growth, the economic implication is that the average income of regions in low initial development level grows faster than the regions in high initial development level, and achieving steady economic growth in the end. At present, some scholars have paid some attention to Chinese tourism economic convergence, such as H.N. Jiang etc. (2009), Y. Fang etc.(2014).

As a tourism province, Zhejiang's tourism economy in the lead at China over years, but it also exist the disequilibrium phenomenon of regional tourism economic. Northern Zhejiang, where Hangzhou is located, and eastern Zhejiang, where Ningbo is located, play an important role in the strategy of speeding up tourism industrial transforming and upgrading. In this background, whether Zhejiang's Tourism Economy will polarized or not, whether long-term trend of Inter-regional gap will expand or narrow. Based on the above analysis, this paper will test the existence of three hypotheses of convergence: $\alpha$-convergence, $\beta$-convergence and Club convergence of Zhejiang's tourism economy.

\section{METHODS AND DATA}

\subsection{Convergence Test}

In Economic Growth Theory, there are three main hypotheses of convergence: $\alpha$-convergence, $\beta$ convergence and Club convergence, according to different assumptions of convergence conditions. $\alpha$ convergence refers to the trend of dispersion of output per person on different economies gradually decrease; $\beta$-convergence includes absolute $\beta$ convergence and conditional $\beta$-convergence, whose 
implications is that economic growth has a negative correlation between economic level and economic growth rate, which implies developing regions have a higher growth rate than developed regions. The absolute convergence refers to no matter what the initial conditions and economic structure is, all regions will converge to the same steady-state level. The conditional convergence refers to no matter what the initial conditions are, different regions will eventually converge to their own steady-state level because of existing the factors which affecting the steady-state level. Club convergence requires economies should have similar economic structures and similar initial conditions, when the two conditions are combined, each region will eventually converge to their own steady-state level(Shen,2012).

\subsection{1 $\alpha$-Convergence Test}

$\alpha$-convergence uses logarithmic standard deviation of tourist income per person as indicator. The $\alpha$ convergence phenomenon exists if regional logarithmic standard deviation of tourist income per person decreases. It is calculated as:

$$
\sigma_{t}=\sqrt{\frac{1}{n} \sum_{i=1}^{n}\left(\ln X_{i t}-\ln \bar{X}\right)^{2}}
$$

In the formula: $X_{i t}$ is tourist income per person for region $\mathrm{i}$ in year $\mathrm{t}, \quad n$ is the number of cities $(\mathrm{n}=11)$.

\subsection{2 $\beta$-Convergence Test}

This paper uses classical Barro regression equation to test absolute $\beta$-convergence of Zhejiang's tourism economy. The test method is cross-section regression, if the coefficient $\beta$ is negative and statistically significant, namely the level of regional tourism economy and its growth rate has negative relation. It indicates the absolute $\beta$-convergence exists.

\subsubsection{Club Convergence Test}

This paper tests whether the club convergence exists or not under the theory of decomposition of Theil index, which suggested by S.X.Wang (2011) and W.Q. Pan(2013). Club convergence need to satisfy two conditions: convergence exists in four regions of Zhejiang province; but no convergence in interregions. We divides 11 cities of Zhejiang province into four regions according to the statistical yearbook of Zhejiang province: Northern (Hangzhou, Jiaxing, Huzhou,Shaoxing), Eastern (Ningbo, Taizhou, Zhoushan), central (Jinhua, Quzhou), South (Wenzhou, Lishui). Theil index can be divided into difference of four regions $\left(\mathrm{T}_{\mathrm{BR}}\right)$ and difference of inter-regions ( $\left.\mathrm{T}_{\mathrm{WR}}\right)$.

\subsection{Data}

This paper uses Zhejiang's tourism income, domestic tourism income, inbound tourism income and population data from 2000 to 2012. Data all comes from the Statistical Yearbook of Zhejiang province. In the test of convergence, tourism income has been deflated to remove price factors based on year 2000 data.

\section{ANALYSIS OF THE SPATIAL-TEMPORAL DIFFERENCE OF ZHEJIANG'S TOURISM ECONOMY}

\subsection{Analysis of Total Difference}

In order to analyze the total temporal and spatial difference of tourism more accurately for Zhejiang province, this paper studies not only the differences of tourism income, but also decompose it, to calculate coefficient of variation of total tourism income, domestic tourism income and inbound tourism for years. We can find some characteristics of total difference of Zhejiang's tourism economy: (1) In general, the total differences of Zhejiang tourism economic development has been gradually narrowed, value of has decreased from 1.13 in 2000 to 0.72 in 2012, which also reflects on the differences of domestic tourism and inbound tourism. The difference is mainly caused by the fact that the tourism income of regions deviates from the average level of province. (2)The difference of inbound tourism is larger than that of domestic tourism and the difference can be explained as the different condition. Compared to domestic tourism, inbound tourism depends more on location, tourism resource endowment, openness, and so on.

\subsection{The decomposition of Gini coefficient of Total difference}

The trend of coefficient of variation reflects the total regional differences of tourism economy, but it can not analyze the source and formation of differences. The paper takes structural decomposition of total differences of tourism economy under the theory of decomposition of Gini coefficient. In table $1, \mathrm{G}, \mathrm{G}_{\mathrm{d}}$, $\mathrm{G}_{\mathrm{f}}$ represent Gini coefficient of total tourism income, domestic tourism income, inbound tourism income (foreign currency) respectively. $S_{d}, S_{f}$ represent the domestic proportion and inbound proportion in total tourism income respectively. $\mathrm{P}_{\mathrm{d}}, \mathrm{P}_{\mathrm{f}}$ represent contribution rates of Gini Coefficient of domestic tourism income, inbound tourism income (foreign currency) respectively.

Table 1 indicates: (1) The Gini coefficient of total tourism income is decreasing year by year. This means the differences of Zhejiang's tourism economy tend to narrow Since 2000, and the distribution of tourism income develop from a larger 
gap to reasonability.(2)See from Gini contribution rate, over the years the rate of domestic tourism to total difference is greater than the rate of inbound tourism, the average contribution rate reached $83 \%$. Thus it can be recognized that the differences of tourism economy in Zhejiang is mainly caused by the difference of domestic tourism, and its reason is that the domestic tourism income accounted for a larger share of total tourism income, the average share is as high as 92\%.(3)See From the trend of Gini coefficient, over the years the Gini coefficient of inbound tourism income is greater than of domestic tourism income, it also shows the difference of inbound tourism is larger than domestic tourism.

Table 1 Structural decomposition of total tourism income

\begin{tabular}{|c|c|c|c|c|c|c|c|}
\hline & \multicolumn{2}{|c|}{$\begin{array}{c}\text { Gini coefficient of } \\
\text { total and } \\
\text { decomposition }\end{array}$} & \multicolumn{2}{c|}{$\begin{array}{c}\text { domestic and } \\
\text { inbound } \\
\text { proportion }\end{array}$} & \multicolumn{2}{c|}{$\begin{array}{c}\text { contribution } \\
\text { rates of Gini } \\
\text { Coefficient \% }\end{array}$} \\
\cline { 2 - 8 } & $\mathrm{G}$ & $\mathrm{G}_{\mathrm{f}}$ & $\mathrm{G}_{\mathrm{d}}$ & $\mathrm{S}_{\mathrm{f}}$ & $\mathrm{S}_{\mathrm{d}}$ & $\mathrm{P}_{\mathrm{f}}$ & $\mathrm{P}_{\mathrm{d}}$ \\
\hline 2000 & 0.35 & 0.52 & 0.34 & 0.07 & 0.93 & 0.10 & 0.90 \\
\hline 2001 & 0.31 & 0.49 & 0.30 & 0.08 & 0.92 & 0.13 & 0.87 \\
\hline 2002 & 0.20 & 0.45 & 0.18 & 0.08 & 0.92 & 0.18 & 0.82 \\
\hline 2003 & 0.29 & 0.43 & 0.27 & 0.07 & 0.93 & 0.11 & 0.89 \\
\hline 2004 & 0.26 & 0.42 & 0.24 & 0.09 & 0.91 & 0.14 & 0.86 \\
\hline 2005 & 0.26 & 0.42 & 0.24 & 0.09 & 0.91 & 0.15 & 0.85 \\
\hline 2006 & 0.23 & 0.42 & 0.21 & 0.09 & 0.91 & 0.17 & 0.83 \\
\hline 2007 & 0.21 & 0.42 & 0.18 & 0.09 & 0.91 & 0.19 & 0.81 \\
\hline 2008 & 0.19 & 0.42 & 0.17 & 0.08 & 0.92 & 0.18 & 0.82 \\
\hline 2009 & 0.18 & 0.47 & 0.16 & 0.07 & 0.93 & 0.18 & 0.82 \\
\hline 2010 & 0.14 & 0.44 & 0.12 & 0.07 & 0.93 & 0.21 & 0.79 \\
\hline 2011 & 0.12 & 0.38 & 0.10 & 0.07 & 0.93 & 0.22 & 0.78 \\
\hline 2012 & 0.10 & 0.38 & 0.09 & 0.06 & 0.94 & 0.22 & 0.78 \\
\hline
\end{tabular}

\subsection{Analysis of Regional difference}

Analysis on the differences of regional tourism development in Zhejiang can be taken from Inter to intra district differences respectively. Inter regional differences can be measured by the coefficient of variation of tourism income proportion of each region respectively, and intra regional differences are still measured by the coefficient of variation of tourism income.

Figure 1 shows: (1) Regional differences of total tourism income are higher than internal differences of the east region, but lower than other regions. This is mainly caused by internal differences of the north of Zhejiang, and the total trend of regional differences tends to reduce. (2) From interior of the region, the order of differences of regions is north> south> middle> east. The difference trends of regions are consistent except the east of Zhejiang. Normally speaking, the internal differences reached the maximum in 2005, then decreased gradually.

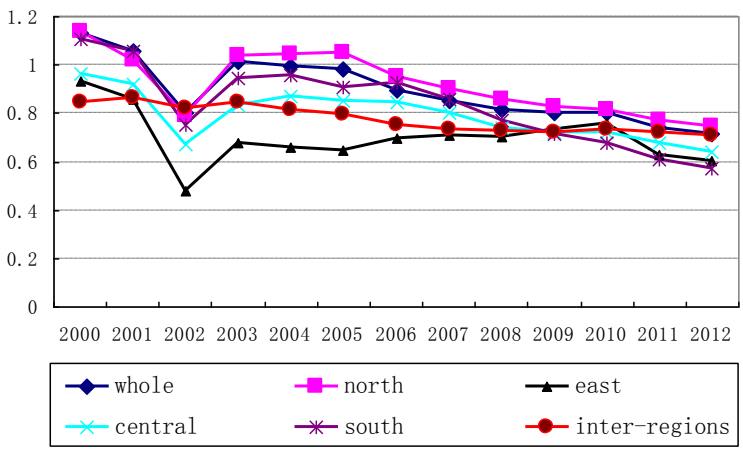

Figure 1 Trends of regional difference of total tourism income

\section{CONVERGENCE OF ZHEJIANG'S TOURISM ECONOMY}

\section{$4.1 \alpha$-Convergence}

Through computing the logarithmic standard deviation of per capita income of tourism cities (2000-2012), the results show: firstly, Figure 2 display that $\alpha$-index has a downward trend, it means Zhejiang's tourism economy exist $\alpha$-convergence. Secondly, $\alpha$-convergence has a obvious inflexion in 2003 , it is mainly caused by the "SARS" on the impact of tourism. Thirdly, from the regional perspective, $\alpha$-index ranking from high to low for areas is: the south, central, north and east, it means the southern and central region has a greater difference of per capita income of tourism cities than the northern and eastern region. Fourthly, for the interior of each region, other regions' $\alpha$-index changed more intensively and complicatedly than the northern. However, because of the weight of northern area is so large that it did not change the consistent trend between whole province and the north of Zhejiang.

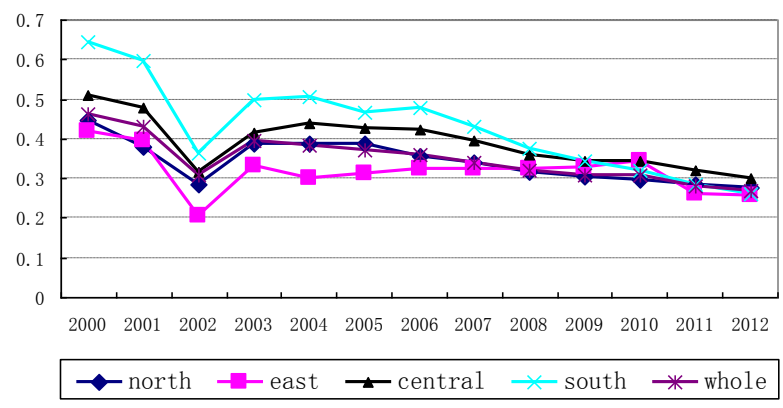

Figure 2 The $\alpha$-convergence of regional tourism

\section{$4.2 \beta$-Convergence}

Use the Formula (5) to test the $\beta$-Convergence of Zhejiang's tourism economy (2000-2012), if $\beta$ less than 0 and is statistically significant, it means there is a negative correlation of tourist economy level and growth rate, namely the existence of absolute convergence. The results show that in the 2000 2012 period, $\beta=-0.033$, and it is significant at $1 \%$ probability level, it means existence of absolute $\beta$ - 
convergence of Zhejiang's tourism economy, and the convergence rate is $3.3 \%$. The result is consistent with the $\alpha$-Convergence test. It also confirms that the $\beta$-convergence is a necessary condition for $\alpha$ convergence. It suggests that we keep the speed of tourism economic development in backward area higher than advanced area can realize the convergence of per capita income for regions.

Table $2 \beta$-convergence test

\begin{tabular}{|c|c|c|c|}
\hline & Coefficient & T statistics & Prob. \\
\hline$\alpha$ & 0.257 & 13.731 & 0.000 \\
\hline$\beta$ & -0.033 & 9.816 & 0.000 \\
\hline $\mathrm{R}^{2}$ & 0.915 & & \\
\hline
\end{tabular}

\subsection{Club convergence}

The Theil index of inter and intra district will be calculated in this part. As shown in the Figure 3, Firstly, The total difference of tourism economy in Zhejiang province was reduced yearly. This difference is contributed by inter and intra district differences, both contribute nearly ratio, the difference of intra district is slightly higher than the inter district. Secondly, the internal differences of regions also reduced yearly, showing a trend of convergence, and differences between regions also showed a downward trend .Combined with the definition of club convergence given by Galor (1996), there is not club convergence of Zhejiang's tourism economy. Four regional internal differences tend to narrow, and the differences between regions are also diminishing. Therefore, Zhejiang's tourism economy did not appear the phenomenon that the rich are very rich and the poor are extremely poor.
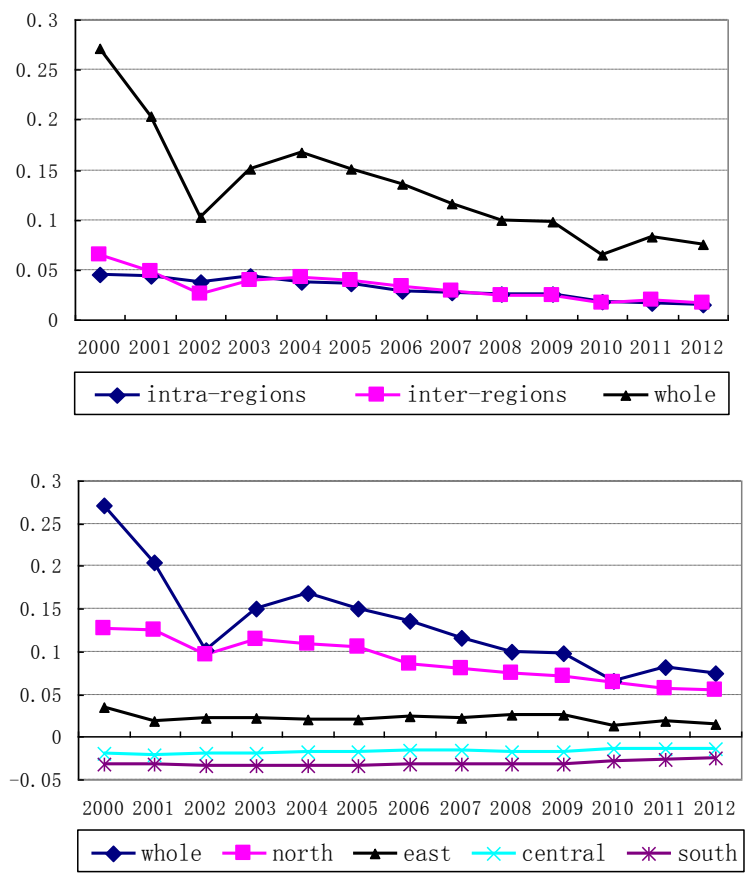

Figure 3 Theil index of tourism economy in Zhejiang Province

\section{CONCLUSIONS}

This paper uses data of Zhejiang's tourism economy to check existence of convergence and describe its characteristics under Economic Growth Convergence Hypothesis. We have several conclusions:

(1) The total difference of Zhejiang's tourism economy was reduced yearly in a long time span. When decompose the differences, we find it is mainly caused by the domestic tourism. And the difference degree of inbound tourism is higher than that of domestic tourism. Domestic tourism difference tends to be more reasonable, but inbound tourism difference is still large. Zhejiang should focus on the development of domestic tourism, to exert its influence on the balance of regional differences; second, make some effective tourism development policy for narrowing differences between areas.

(2)Zhejiang's tourism economy exist $\alpha$ convergence and absolute $\beta$-Convergence, it means tourism per capita income will converge to the same steady-state level for each area. So no matter whether there are differences between the initial level of tourism economy or structure feature in various regions, the difference of regional tourism economy in Zhejiang will be gradually reduced and eventually to achieve stable development.

(3)The research did not find the phenomenon that the rich are very rich and the poor are extremely poor in Zhejiang, namely it is not exist club convergence. The internal differences in the Yangtze River Delta region and other regions are less, as well as differences between regions.

\section{REFERENCES}

[1] Barro R J, Sala-i-Martin X. 1992. Convergence, Journal of Political Economy, Vol.100 (2): 223-251.

[2] Galor O. 1996. Convergence? Inferences from Theoretical Models, Economic Journal, Vol.106, No, 437: 1056-1069.

[3] H.N. Jiang, Y.Q. Lu, G.Q. Lv. 2009. A Study on the Regional Differences of inbound Tourism Economy in Jiangsu Province. Tourism Tribune, Vol.1:23-28.

[4] Sala-i-Martin X. 1995. The Classical Approach to Convergence Analysis, Centre for Economic Policy Research.

[5] S.X. Wang, Y.Q. He, X.D Wang. 2011. A study on the Characteristics and Influencing Factors of China Tourism Economy, Journal of Business Economics, Vol.234 (4):8996.

[6] W.Q. Pan. 2010. The Economic Disparity between Different Regions of China and Its Reduction) an Analysis from the Geographical Perspective, Social Sciences in China, Vol.1: 72-84.

[7] Y. Fang, X.H, Bian. 2014. The Evolution Analysis to the space-time Difference of Tourism Economy in Yangtze River Delta. Tourism Forum, Vol.2:50-56. 